\title{
Preface: The Phantom of Chance
}

It is difficult to write a book about something that does not exist. For a brilliant novelist like Flaubert, the dream of writing a book about nothing - un livre sur rien - is tempting, but for the more pedestrian scholarly writer who depends on an object to describe there is something hopeless about such a project. So a book about chance in seventeenthcentury France, the high point of rationalist thought, seems to be condemned even before it begins. Lorraine Daston writes eloquently:

In the clamorous debates of seventeenth-century philosophy [...] there was one unisonal chord struck: the unanimous and resounding rejection of the reality of fortune. Antipathy to fortune united Protestant and Catholic, mechanical philosopher and Cambridge Platonist, Hobbesian with Christian virtuoso. $^{1}$

And yet...

The very rationalists who rejected chance - la fortune or le hasard - as being simply a name for human ignorance continued to write as if there were many things that happened by chance. Arnauld and Nicole open their important Logic, or the Art of Thinking (La Logique, ou l'Art de penser, 1683) by saying, 'This little work was born entirely by chance ...' ('La naissance de ce petit ouvrage est due entièrement au hasard ...'). ${ }^{2}$ Descartes writes of 'games of chance, where fortune alone reigns' ('les jeux de hasard, où il n'y a que la fortune seule qui règne'), ${ }^{3}$ and in a celebrated passage of the Discourse on Method speaks of the need for resoluteness in actions, which makes men 'walk always as straight as they can in the same direction, and not to change course for slight reasons, even if, perhaps, only chance at first cause them to choose it'. ${ }^{4}$ Pascal's Pensées abound in examples of oddly random, almost imperceptible things that have enormous consequences. The passages on this theme that have left the most lasting impression are no doubt the ones on Cleopatra's nose and its impact on history, but there are many others. 
If then, as Daston says, the 'vulgar error seventeenth-century philosophers worked hardest to reject was fortune or chance', perhaps we can say that it is impossible to destroy something that does not exist, something that the influential neo-Stoic philosopher and statesman Guillaume du Vair called 'this phantom' ('ce fantosme'). ${ }^{5}$ And even if chance does not exist, the effort to combat it or the belief in it does exist and leaves significant traces, a bit like the hollows left in lava or sandstone where some creature's remains were once enclosed but where the passage of time has left only a void, but a void that bears the shape of something now missing. In a certain sense, most intellectual endeavour consists of the struggle against chance and because chance is the absent and even non-existent adversary, our speech and our writing are formed by this phantom. One of the most frequent expressions in intellectual discourse is 'It is not by chance that...' or 'Ce n'est pas un hasard si ...' In this way, almost everything that we argue is framed by reference to this invisible, non-existent force whose effect we deny to assert our own views.

\section{Starting in the Middle of Things}

Aristotle teaches that stories should start in the middle of things, in medias res. This study started with such a middle, with the riddle of chance that Pierre Corneille, one of the major playwrights and dramatic theorists of the seventeenth century, found in Aristotle's Poetics. In the first paragraph of his major study of the theory of drama, Three Discourses on the Dramatic Poem (Trois discours sur le poème dramatique, 1660), Pierre Corneille quotes Aristotle to say that the good subjects for tragedy come from chance:

Our Doctor says that the Subjects come from Fortune, which makes things happen, and not from Art which imagines them. She is the mistress of Events, and in giving us a choice from among those she presents to us, she implicitly forbids the usurpation by which we would put on the Stage incidents not of her making. ${ }^{6}$

In the midst of the Nicomachean Ethics, Aristotle in turn quotes Agathon to say, 'Art loves chance and chance loves art' (VI. 4. 1140 a $17 \mathrm{ss}) .{ }^{7}$ And yet again, in describing the development and conclusion of the tragic plot, Aristotle mentions chance, but this time to exclude it from tragedy:

Since tragic mimesis portrays not just a whole action, but events which are fearful and pitiful, this can best be achieved when things occur contrary to 
expectation yet still on account of one another. A sense of wonder will be more likely to be aroused in this way than as a result of the arbitrary or fortuitous, since even chance events make the greatest impact of wonder when they appear to have a purpose (as in the case where Mitys's statue at Argos fell on Mitys's murderer and killed him, while he was looking at it: such things do not seem to happen without reason). So, then, plot-structures which embody this principle must be superior. (1452a1-10, chap. 9) ${ }^{8}$

In all three cases the term used by Aristotle was tyche. Thus the relation of chance to art, and especially to literary art and drama, has a respectably ancient and tantalisingly obscure basis. And, like any concept conveyed in a series of words over several millennia and in multiple languages, the study of 'chance' requires, at the least, incessant attention to at least three moments: that of the authors of antiquity whose ideas became the basis, or the pretext, for much writing in the early-modern period, that of the writers of the sixteenth and seventeenth centuries themselves, and our own moment with its concerns through which we attempt to understand the past.

Was Corneille's discovery of this puzzle an isolated case, or did the problem of chance draw the interest of other writers in this period? The more one looks, the more chance seems to be ubiquitous as an object of study and as an object of scorn in the early-modern period. This makes sense in the intellectual history of this time. Here are a few preliminary speculations about why chance might come to the fore in this period throughout the spectrum of writing, both in the 'poetic' genres of fictional narrative, lyric poetry and in the philosophical, political and religious writing in which chance is either advanced as an important factor in human life or on the contrary discounted.

First, and most obvious, is the fact that popular literature has always included a large dose of chance - we need only to think of fabliaux or romances to find many examples of chance, some of them at or beyond the limits of the plausible. The association of the romance with chance was so utterly taken for granted that when the recognised author of one of the major novels of the period, Marie-Madeleine de Lafayette, wrote about her Princess of Cleves she claimed that it could not be considered a roman (a romance) because it was not at all 'romanesque', apparently meaning that it was more believable and coherent, lacking in the extraordinary coincidences that had come to be associated with the roman. ${ }^{9}$ This popular tradition of literature, lacking in the doctrinaire spirit of much of the neo-Aristotelian poetics that flourished in France in the mid-1600s, had not needed to make an inventory and provide a theoretical justification of events that just seemed to happen, often with little reason, but the early moderns developed such a hair-trigger 
sensitivity to questions about cause, effect and motivation that anything that seemed to be chance stood out. This was particularly the case after the debates surrounding Corneille's Le Cid in 1637.

Second, the significant revival of Stoic thought in the late sixteenth century thrust chance into the forefront, though in a quite paradoxical way. Much Stoic writing can have the effect of accentuating the apparent ubiquity of accidents, shipwrecks, conflagrations and sudden death. This may appear strange, since the Stoics are widely known to have believed in providence rather than in chance. Pierre Aubenque, in comparing Aristotle with the Stoics, notes that while Aristotle believed that the world is rational only in the higher spheres but not in the lower ones, within which there are all kinds of misfires and monsters engendered by matter that is not controlled by the forms, the Stoics on the other hand believed that the world is already rational throughout. ${ }^{10}$ However, as a practical matter, followers of the Stoics needed to accept that everyday life seemed, at least, to be full of inexplicable, unforeseeable and uncontrollable events. Not being able to change the world, the Stoic needed to get used to what appears to be chance: 'The wise man does not act upon the world but rather follows it, attunes his private life to the universal harmony, makes himself consent to the decrees of a Providence that, even under the inevitable appearance of evil, remains the highest expression of the Logos. ${ }^{11}$ But to teach this lesson, and to urge their followers to practise the mastery of imagination and passions, neo-Stoics, like their ancient forebears, needed to contrast and to model the serene acceptance of the wise man with the pathetic exaggeration of external ills typical of ordinary people. As a consequence, Stoic and neo-Stoic writing is full of calamity and contingent events, full of apparent chance.

A third development, sometimes difficult to separate from neoStoicism, is that rise of sceptical thought generally called libertinage or 'free-thought' which was endowed with a great deal of energy by Montaigne's Essays. ${ }^{12}$ The Essays were written during the wars of religion, which themselves created for some a backlash of doubt, and at a moment of renewed attention to ancient philosophers other than Aristotle, including the Sceptics and Epicureans (through Lucretius). These two circumstances shaped Montaigne's book, which became a manual for Sceptics and free-thinkers for many decades after its publication in 1580. With Montaigne we can see the formation of a major problematics of chance both large-scale and small-scale. On the small scale there is an emphasis on the unpredictability of any individual's life. The falling roof tile in 'That to philosophise is to learn to die' ('Que philosopher c'est apprendre à mourir') represents the unpredictable, sudden and trivial cause that can end life at any moment in any place. 
But less dramatic aspects of a person's life are also apparently random: one's tastes and opinions vary unaccountably from one day to the next. On the larger scale, Montaigne shows that political, military and judicial doctrines are all the result of chance and subject to it. Consider the complementarity of such essays as (the very first one) 'By diverse means we arrive at the same end' (I. 1) and 'Various outcomes of the same plan' (I. 24). Even more significantly, Montaigne makes striking use of a method that for centuries afterward was the central basis for sceptical arguments against religion and the established order, the method of cumulative cultural comparison. In his long chapter on the 'Apology for Raymond Sebond', Montaigne teaches something quite striking about chance. It is tempting, when first thinking about chance, to suppose that chance displays itself in utter disorder, in the absence of system. Montaigne's insight here, as he juxtaposes complex cultural arrangements, is that chance often appears with special clarity as a manifestation of an excess of order or system. This happens at the boundaries of systems, when they encounter each other, and when the smooth and apparently logical working of an ethical or legal code appears laughably arbitrary next to its mirror image in another culture, where comparable units of value appear transposed. In one, incest is held to be the most hateful, unnatural crime while in another incest is held to be virtuous. The consequence for the sceptic is to advance the claim that the contradictory manifestations of order cancel out the claim to an overall order and leave the conclusion that the world is ruled only by chance, and this view conformed nicely with Lucretian philosophy, which was gaining ground for many reasons and which gave chance the fundamental role in the creation of the universe. Libertines did not shrink from emphasising the discrepancy between a Christian view of the world as created for man and centred upon mankind (the image of God) and evidence of disorder, imperfection and non-anthropocentricism in the cosmos (in this view we can see why heliocentric astronomy appeared so threatening to the Church) - all themes found in Montaigne's 'Apology'. ${ }^{13}$ Libertine writers sometimes associated themselves with the neo-Stoic movement, one may think of La Mothe Le Vayer's On the Virtue of the Pagans (De la vertu des païens, 1641), making it difficult to distinguish neo-Stoics in general from the more subversive thinkers so feared by Garasse and many others in the Church. As Christian writers (or even simply writers sponsored by the state and wishing to remain within official orthodoxy) pushed back against that movement of thought many approaches are deployed to explain, and sometimes to explain away, the apparent contingency of the world as people experienced it. ${ }^{14}$

Seventeenth-century France reacted against the wars of the sixteenth 
century and against Montaigne's triumphant scepticism. Centralised monarchical administration and renewed religious orthodoxy created institutional stability on a level not seen before. In literature and philosophy as well, France reacted against scepticism. Both Descartes and Pascal, with different approaches, attempted to provide a rational basis for religious faith and at the same time make major use of a concept that in certain respects eliminates chance: the idea of the machine. If chance is mysterious, unpredictable and unique (infrequent, not subject to repetition) the machine is the opposite: its functioning is clear, entirely predictable and repetitious. For Descartes the machine was the basis for all animal life and for Pascal it had even more extensive applications, ranging from the first arithmetic machine (or calculator) to an account of human life as a whole to the extent that we are controlled by thoughtless and repetitive routines. We recognise the mathesis universalis of Foucault but in a more dynamic form. In one of the most noted achievements of seventeenth-century science, the creation of the calculus of probabilities, Pascal and other thinkers tried to tame chance and increase predictability even in the domain where it seemed supreme and ineradicable, the games of chance, jeux de hasard. It would seem that, at least until the return of chance in the form of the je ne sais quoi, the seventeenth century aimed at eliminating chance in social institutions and in thought.

Yet in reacting against chance, seventeenth-century French culture actually incorporated chance on a deeper level. There has been much attention to rationality and mechanism in the seventeenth century but less to the role that chance continued to play. However, from what we know about mimesis, in part from René Girard's work, any struggle against something risks producing a mirror image of the foe. At the very least, chance appears as a trace within the procedures and representations designed to contain it. Thus the literary doctrines that urge plausibility (or verisimilitude) in plots give evidence of - and provide further stimulus for - a lively sensitivity to the appearance of chance.

Fourth, the attention to chance in the seventeenth century derives from the renewed vigour of the 'lower' forms of investigation of natural phenomena, including medicine, which was not yet a science, and the gradual acceptance of empirical approaches, as Ian Hacking has shown in The Emergence of Probability. The everyday observation of life led to a certain practical know-how, but this know-how, even in highly developed crafts, could simply not be considered knowledge, that is scientia, for knowledge had to be arrived at by demonstration, that is deductively, as opposed to opinion, derived from sensation - including observation - which was aestimatio: 'In scholastic doctrine opinion is 
the bearer of probability. The limit of increasing probability of opinion might be certain belief, but it is not knowledge: not because it lacks some missing ingredient, but because in general the objects of opinion are not the kinds of proposition that can be objects of knowledge. ${ }^{15}$ The emergence of probability, that is a way of dealing with the imperfect and contingent material world, occurred when 'internal evidence', that is the evidence from things themselves, was admitted as a form of proof. This evidence from material things themselves came primarily from the 'low sciences': alchemy, geology, astrology and medicine. The high sciences such as optics, astronomy and mechanics still clung to demonstration and scorned opinion. ${ }^{16}$ Francis Bacon, as Michael Witmore and others have shown, saw the artificial cultivation of accident through experimentation as a way of thwarting the powerful inherited tendency toward deductive reasoning. ${ }^{17}$ On the other hand, Descartes attempted to create a foundation for science by eliminating circumstance and the contingent in general. In direct contrast to Montaigne, whom Ann Hartle has called an 'accidental philosopher', Descartes wished to be a philosopher of the necessary. ${ }^{18}$

In these four streams of converging influences that pushed chance to the forefront, we can see a common thread, the distinction between the 'high' and the 'low', the 'certain' and timeless sphere of spirit or intellect and the 'contingent' or irrational sphere of everyday and quite imperfect life. In literary debates, chance events, though common in much drama and narrative, were decried as being implausible and as showing what did happen rather than what should happen. Much effort was expended to eliminate or at least to contain and 'explain' chance events in a literature that was taken seriously and held to a higher theoretical standard. In philosophical and theological debates, much needed to be done to describe, if not to explain, how an omnipotent and eternal divinity could have created a world of such apparent injustice and randomness. And in the branch of philosophy that emerged into what we call science, there was turbulence on the boundary between the 'higher' world of theory and the 'lower' world of observable events.

\section{The End of Fortune and the Rise of Chance}

The primary purpose of the present study is to explore what happened when 'fortune' yielded to other types of chance. Our hypothesis is that a view of chance that existed for millennia and that was expressed in early-modern French primarily with the term hasard (though other words convey the same or closely related ideas such as rencontre and 
aventure) took on renewed life while 'fortune' waned. It is not simply that the word fortune appears less frequently (though that is in fact the case) but that new circumstances and new arguments made it desirable to use terms that conveyed a newly fragmentary, demystified and somewhat trivialised conception of unexpected events. The texts studied here are all broadly within the literary field. The concept 'literary' itself is relatively new and is forged out of what the seventeenth century would have considered poetry on the one hand - tragedy, comedy, prose narrative - and eloquence on the other. Thus we are not specifically concerned with philosophical and theological debates except to the extent that they influenced or were expressed in the literary domain.

The idea that fortune fell at the end of the Renaissance is not in itself new. ${ }^{19}$ But there are many ways of understanding the results, ways that derive in part from different disciplinary approaches (history of science, philosophy, and literary study) and in part from the specific objects that one studies. One way of understanding fortune's fall is to understand fortune as representing chance as a whole and to see the lowered status of fortune as corresponding to the proportionate and contemporaneous rise in world-views based on mechanism and determinism. We will encounter this view in the course of the present study but it is not the path that we will pursue. Instead, we will see how chance persisted but in a new form and within literature.

In studying 'chance' or any other concept that has been shared by many cultures throughout millennia - 'God', 'freedom', 'truth', 'beauty' and other such concepts come to mind - we realise that we are confronted with a scale of juxtaposed ideas and terms, terms that are neither clearly distinct nor entirely identical. In approaching early-modern ideas of chance we first need to look back at the tradition on which writers like Bossuet, Corneille, Lafayette, Pascal, Racine and others drew and which they reshaped. This tradition assigns a great range of meanings to terms like tyche, casus and fortuna, and they must repeatedly be parsed with respect for the context. Thus when Boethius writes of Fortuna in the early sixth century and when Corneille writes of 'la Fortune' in the seventeenth century, each means to convey the sense of Aristotle's tyche but all three writers have distinctly different ways of using the term and apply it to different cases. However, to anticipate somewhat the general line of the chapters that follow, we can say that after Montaigne, writers in French sought a term to designate events that erupted unpredictably, that could not be foreseen, that defied planning and institutional regularity, that disrupted lives and narratives, and that made a mockery of hierarchies, overturning the respected and apparently logical order of importance among things and people. Increasingly the term used 
for such events was hasard. 'Fortune' could sometimes be used with this new emphasis but was more often used either to designate material wealth and social standing or to convey a rather grandiose sense of dramatic effect and individual importance. In short, it seems that henceforth fortune gathers and organises, subordinates and prioritises, and creates extensive sequences, while hasard (which we will generally simply call 'chance' or 'randomness') erupts and scatters, levels, deflates and trivialises.

There has been surprisingly little attention to the role of chance in early-modern French literature, with the exceptions of Thomas Kavanagh's studies, which emphasise games of chance, and Ross Hamilton's recent Accident. With the exception of a few passages in Pascal, Hamilton does not examine any of the authors who are included in the present study. ${ }^{20}$ With regard to games of chance, which are considered briefly in the chapter on Pascal, they appear as a flight from chance. That is, if a chance event is one which happens suddenly, unexpectedly and yet appears to be significant, games of chance constitute a way of constraining and limiting the appearance of the fortuitous, almost as if to conjure the danger of chance by limiting its appearance within a ritual. The work most closely related to the present volume in terms of its scope is a recent collection of essays on early-modern chance and literature Chance, Literature, and Culture in Early-Modern France. The Phantom of Chance does not constitute a systematic history of chance in the early-modern French literary field. It proposes instead, more modestly, a series of exploratory investigations of relatively wellknown works, with the aim of showing how attention to their representation of chance (hasard) sheds new light on the individual texts and the moment that produced them.

The works studied in the five chapters are presented in roughly chronological order. This order allows us to glimpse certain key points on a trajectory that leads from a dramatic, imposing and coherent idea of chance as fortune toward an ever more fragmented, decentred, trivial and shallow view of chance as randomness. Fortune - and a number of other variants of what has been called the 'constellation of chance' varies according to the subjective self-image of characters, and the fall of fortune and the rise of randomness largely parallel a disenchanted view of humanity and its place in the world. ${ }^{21}$ As evidence of this long process, we consider first tragi-comedy and the pivotal work Le Cid, which occasioned a justification of a poetics that simulates chance. Then we look at Pascal's Provincial Letters (Lettres provinciales) and Pensées to examine the role of chance in his arguments for a rigorous Christianity. In the year that saw the publication of the Pensées, 
Lafayette's Zayde uses the form of a romance (a genre characterised by its spectacular inclusion of chance incidents) to show how chance appears at the intersection of events and of the characters' individual fears and desires. Eight years later the same author, in a novel usually considered to break away from implausible romance plots, showed that in the new, apparently more realistic narratives, chance had not disappeared but instead took on a new look. While Lafayette was writing her The Princess of Cleves, the influential bishop Bossuet was completing his Discourse on Universal History (Discours sur l'histoire universelle), an authoritative expression of the view that all is governed by God's providence. Surprisingly, Bossuet's argument requires a heightened perception that the historical world operates randomly. His contemporary and acquaintance at the court of Louis XIV, Racine, may have drawn the idea for his final tragedy, Athalie, from Bossuet's history. This drama, often considered the playwright's expression of a predestined, ineluctable fate, shares with Bossuet a double vision of human life, one that appears on a certain level random and on another level driven by eternal purpose. Finally, La Bruyère, a 'moralist' who declares that he portrays the conduct and values of late-century Paris, shows a world spasmodically organised around mere accident (in the sense of coincidence) but also a world that gives an excess role to accident (in the philosophical sense of inessential quality).

\section{Notes}

1. Daston, 'Fortuna and the Passions', p. 26.

2. Arnauld and Nicole, La Logique, p. 29. In this and in the immediately following quotations, italics indicate emphasis added by me.

3. Descartes, Euvres philosophiques, ed. Alquié, III, 679, cited by Emma Gilby, 'The Language of Fortune in Descartes', p. 155

4. Descartes, 'Discours de la méthode', p. 24.

5. Du Vair, De la constance, p. 79. Du Vair's book is in dialogue form, and the expression 'ce fantosme' is attributed to the character named Orphée, who champions the view that all is controlled by God through the forms of nature and of destiny.

6. Corneille, Trois discours sur le poème dramatique, ed. Bénédicte Louvat and Marc Escola, pp. 64-5. Unless otherwise noted, all references to Corneille's Discours will be to this edition. The translation is my own.

7. 'Ainsi sommes-nous autorisés à appliquer à la prudence ce qu'Aristote dit, pour conclure, de l'art: “D'une certaine manière, le domaine de l'art est le même que celui du hasard, comme le dit aussi Agathon: L'art aime le hasard et le hasard aime l'art"' (Aubenque, La Prudence chez Aristote, p. 68). 
8. All quotations from Aristotle will give the conventional location in the Bekker edition of 1831, as here: 1452a1-10. Unless otherwise indicated, the translated passages are from The Poetics of Aristotle, trans. and ed. Stephen Halliwell. This passage is on p. 42.

9. Lafayette, letter to the chevalier de Lescheraine (13 April 1678), quoted in Laugaa, Lectures de Madame de Lafayette, p. 16 note 1.

10. Aubenque, La Prudence chez Aristote, p. 80.

11. Aubenque, La Prudence chez Aristote, p. 87.

12. Montaigne, Essais, ed. Pierre Villey and V.-L. Saulnier and The Complete Essays of Montaigne, trans. Donald M. Frame. All references to the Essais will be to these editions, with parenthetical references to the pages of the respective French or English text, giving the page number of the French text, followed by the page number of the English translation, as 72/49. These texts will be mentioned as Essais, referring to the French text, and Complete Essays, referring to the English translation.

13. In his La Doctrine curieuse des beaux esprits de ce temps (1623), François Garasse, SJ, attacked the wave of atheism that he saw sweeping over France. One of the 'maxims' of the atheists he describes and condemns is an assertion of the dominance of 'destiny' or 'fortune' - concepts he conflates (p. 187).

14. Neo-Stoicism, with its insistence on Providence, can in turn be considered an attempt to counter the multitude of Renaissance writings on 'fortune' and on 'fate'. Jacob Burckhardt claimed that the prominence of Fortune in this period was the result of the spread of scepticism (Gesammelte Werke, III, 347-8). See Howard, 'Jacob Burckhardt, Religion, and the Historiography of "Crisis" and "Transition".

15. Hacking, The Emergence of Probability, p. 22.

16. Hacking, The Emergence of Probability, p. 35.

17. Witmore, Culture of Accidents, p. 113.

18. Ann Hartle, Michel de Montaigne: Accidental Philosopher.

19. Daston writes in her article 'Fortuna and the Passions': 'It is not my goal here to explain how and why Fortuna fell from philosophical grace. Rather, I propose to examine the impact of Fortuna's fall in an area of philosophy traditionally closely intertwined with her vicissitudes, viz. the theory of the passions' (p. 27).

20. Kavanagh, Enlightenment and the Shadows of Chance; Kavanagh, Dice, Cards, Wheels; Kavanagh, Chance, Culture and the Literary Text; Hamilton, Accident.

21. This is the term that Erich Köhler uses to group together the many words used to denote 'chance', 'fortune' and their kindred concepts (Köhler, Le Hasard en littérature). 